\title{
Note
}

\section{Synaptonemal complex analysis of the sex bivalent in goats}

\author{
MEJ Amaral ${ }^{1, *}$, W Jorge ${ }^{2}$ \\ 1 Institut de Biociências, UNESP, Departamento de Genética, \\ Campus de Botucatu, 18.618-000 Botucatu, São Paulo; \\ 2 Universidade Federal de Minas Gerais, Institutó de Cíencias Biologicas, \\ Departamento de Biologia Geral, 31.270-010 Belo Horizonte, Minas Gerais, Brazil
}

(Received 24 February 1993; accepted 7 March 1994)

\begin{abstract}
Summary - Synaptonemal complex (SC) analysis of XY pairing in the goat (Capra hircus; $2 n=60$ ) was investigated by electron microscopy for the first time in this species. Synapsis of the $\mathrm{X}$ and $\mathrm{Y}$ chromosomes begins during the mid-late zygotene stage as the autosomes complete their pairing. Only a small portion of the total length of the $Y$ is paired with the $\mathrm{X}$ chromosome at this time. By the early pachytene, almost $90 \%$ of the $\mathrm{Y}$ is paired with the X. All the observed stages of the sex bivalent pairing showed the structural difference between the differential and pairing regions. In the pairing region, a synaptonemal complex is formed, while in the differential region the chromosome axes remain free.
\end{abstract}

synaptonemal complex / meiosis / pachytene / XY bivalent / goat

Résumé - Analyse du complexe synaptonémique du bivalent sexuel chez la chèvre. $L$ 'analyse en microscopie électronique du complexe synaptonémique (SC) du bivalent sexuel a, pour la première fois, été réalisée chez la chèvre. Le processus d'appariement des chromosomes $X$ et $Y$ commence dans la deuxième partie du stade zygotène, lorsque les autosomes arrivent en fin d'appariement. Seule une petite portion de l'Y s'apparie à l'X. Au cours du stade pachytène, 90\% de l'Y est apparié d̀ l'X. Toutes les étapes observées de l'appariement du bivalent sexuel montrent une différence de structure entre les régions appariées et celles non appariées. Dans la région d'appariement, un complexe synaptonémique se forme tandis que dans la région différentielle les axes chromosomiques demeurent libres.

complexe synaptonémique / méiose / pachytène / bivalent XY / chèvre

* Current address: Department of Veterinary Pathobiology, College of Veterinary Medicine, Texas A \& M University, College Station, 77840 TX, USA 


\section{INTRODUCTION}

The sequence of sex bivalent pairing at the meiotic prophase in goats was studied for the first time in this species, in preparations of spermatocytes obtained from males at the beginning of reproductive age. The behavior of the $\mathrm{X}$ and $\mathrm{Y}$ chromosomes at the meiotic prophase of goats was observed by electron microscopy (em). The morphological changes of the sexual pair observed at pachytene are described here.

\section{MATERIALS AND METHODS}

Testicular biopsies were obtained from 2 Saanen buck-goats (Capra hircus; $2 n=60$ ).

The preparations of microspread samples were made according to the technique presented by Solari (1980). A droplet of the testicular cell suspension was added to approximately $5 \mathrm{ml}$ of a $0.5 \% \mathrm{NaCl}$ hypotonic solution. The spread nuclei were then picked up by touching slides pre-coated with plastic film to the surface of the solution. The slides were immediately immersed in a Coplin jar containing SDS fixative (4\% paraformaldehyde and $0.03 \%$ SDS, $\mathrm{pH} 8$, adjusted with sodium tetraborate buffer) and incubated for $5 \mathrm{~min}$ at room temperature. The slides were then held on the surface of the $0.4 \%$ Photoflo, $\mathrm{pH} 8$ for $30 \mathrm{~s}$ and allowed to air dry. Silver-nitrate staining was performed as described by Howell and Black (1980). Nuclei were selected by light microscopy and covered with 50 or 75 mesh grids. The plastic film with the attached nuclei and grids was detached from the slide by floating on water and collected with resined paper. The magnification under em was $4200 \times$. Micrographs were enlarged $5 \times$. The XY bivalent was photographed individually for detailed analysis.

\section{RESULTS}

The XY bivalent was observed in 70 spermatocytes. Thirty cells were complete, with 28 normal autosomal bivalents and one XY bivalent (fig 1 ). Forty cells were incomplete due to cellular disruption and overlapping of the grid network but the analysis of the sexual bivalent was possible.

The unpaired sex chromosome axes showed thickening and stronger staining, allowing easy identification (fig 1a). Figure 2 shows the sex bivalent at mid-late zygotene, when the $\mathrm{X}$ and $\mathrm{Y}$ chromosomes are starting the pairing process. At early pachytene, figure 3 , the $\mathrm{Y}$ chromosome is almost completely paired with the $\mathrm{X}$. In figure 4a the sex bivalent is at mid-pachytene, showing the $\mathrm{X}$ and $\mathrm{Y}$ full pairing. The sex bivalent at late pachytene is presented in figure $4 \mathrm{~b}$, showing the $Y$ chromosome still fully paired with the X.

\section{DISCUSSION}

The $\mathrm{X}$ and $\mathrm{Y}$ chromosomes axes showed a distinct aspect at pachytene, and they clearly differ from the autosomal bivalents, as can be observed in figure 1. At midlate zygotene, when the autosomes are completing their pairing, the $\mathrm{X}$ and $\mathrm{Y}$ begin 


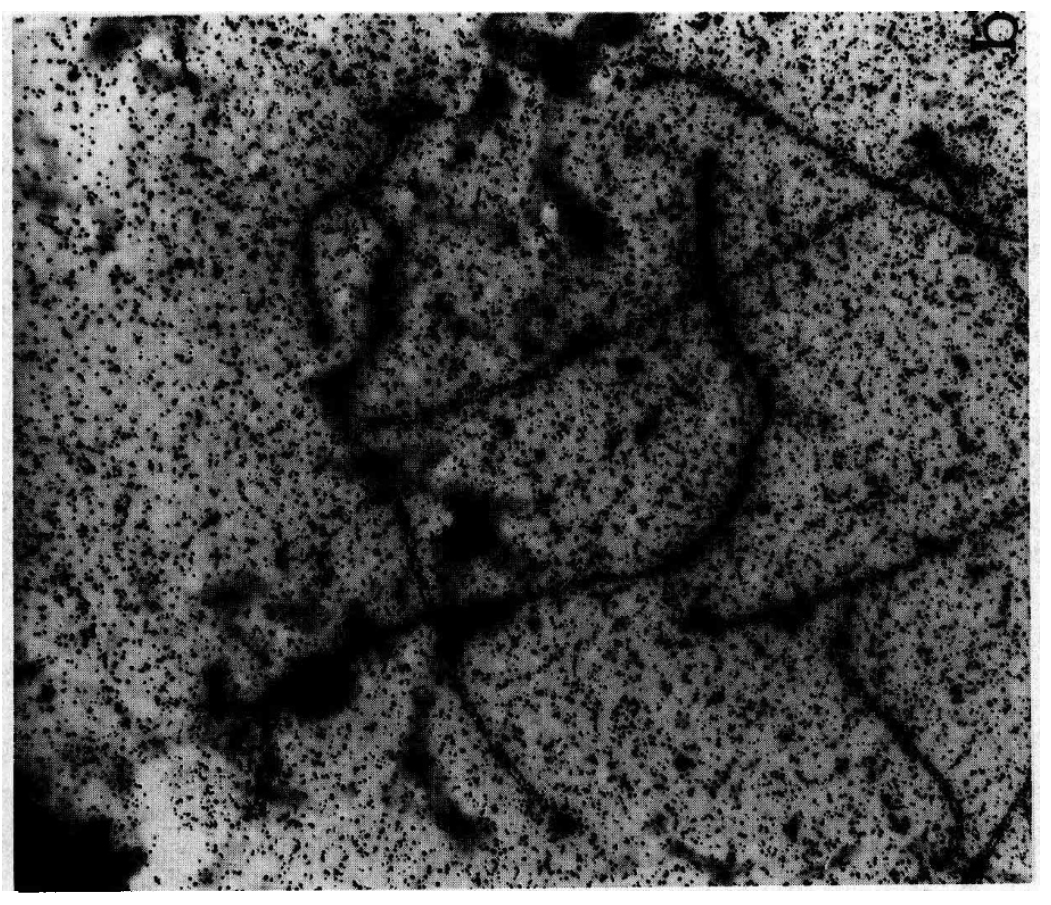

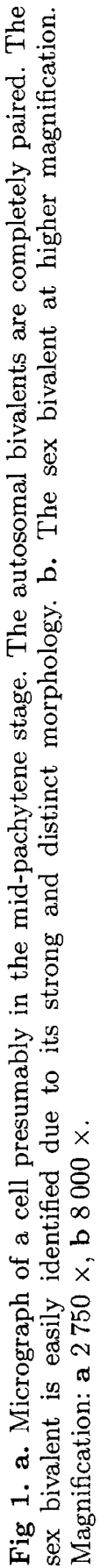




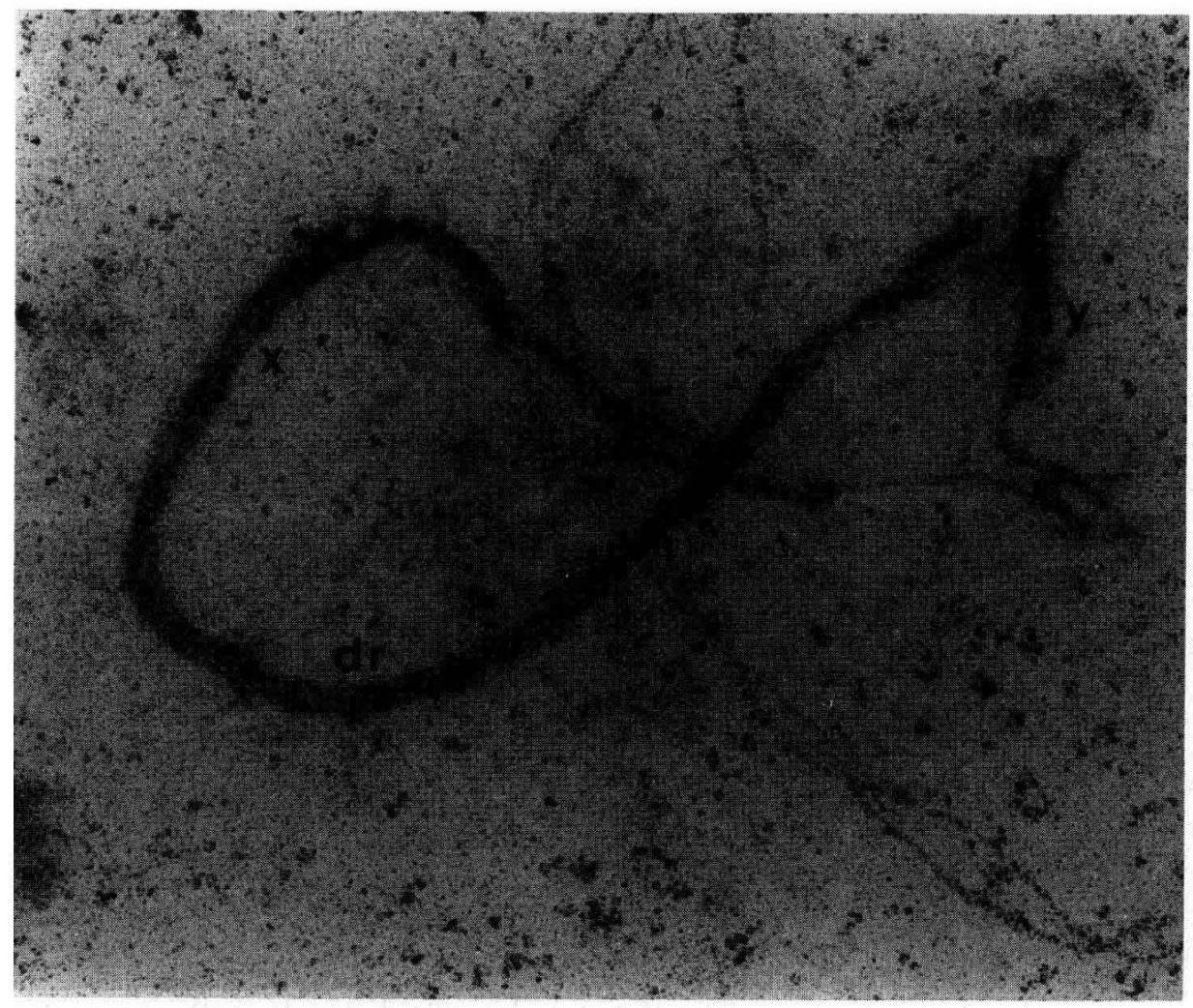

Fig 2. Sex bivalent at mid-late zygotene, when the $X$ and $Y$ chromosomes are starting the pairing process with only a small part of the $Y$ total length paired with the $X$. The unpaired axes (differential region) are thickened. Magnification: $21000 \times$.

the synapsis process with only a small part of the $\mathrm{Y}$ chromosome paired with the $\mathrm{X}$ (figure 2). At the early pachytene, almost $90 \%$ of the $\mathrm{Y}$ is paired with the $\mathrm{X}$ chromosome (figure 3).

All the observed stages of the sex bivalent pair showed the structural difference between the differential and the pairing regions described by Solari (1970) for the serial reconstruction of the mouse XY pair.

In the pairing region, an SC is formed, while in the differential region the chromosome axes are free.

$\mathrm{SC}$ formation is accompanied by a thickening of the differential region of the $\mathrm{X}$ and $\mathrm{Y}$ axes. This thickening has previously been observed in human (Solari, 1980), Chinese hamsters (Moses, 1977), and rats (Joseph and Chandley, 1984) but its meaning is still unknown. In spread technique preparations, this thickening is rarely observed in autosomes, except in non-paired bivalent segments and in univalents.

The morphological changes of the $\mathrm{X}$ and $\mathrm{Y}$ chromosome differential regions, which occur during pachytene, can be used as markers for the identification of their 


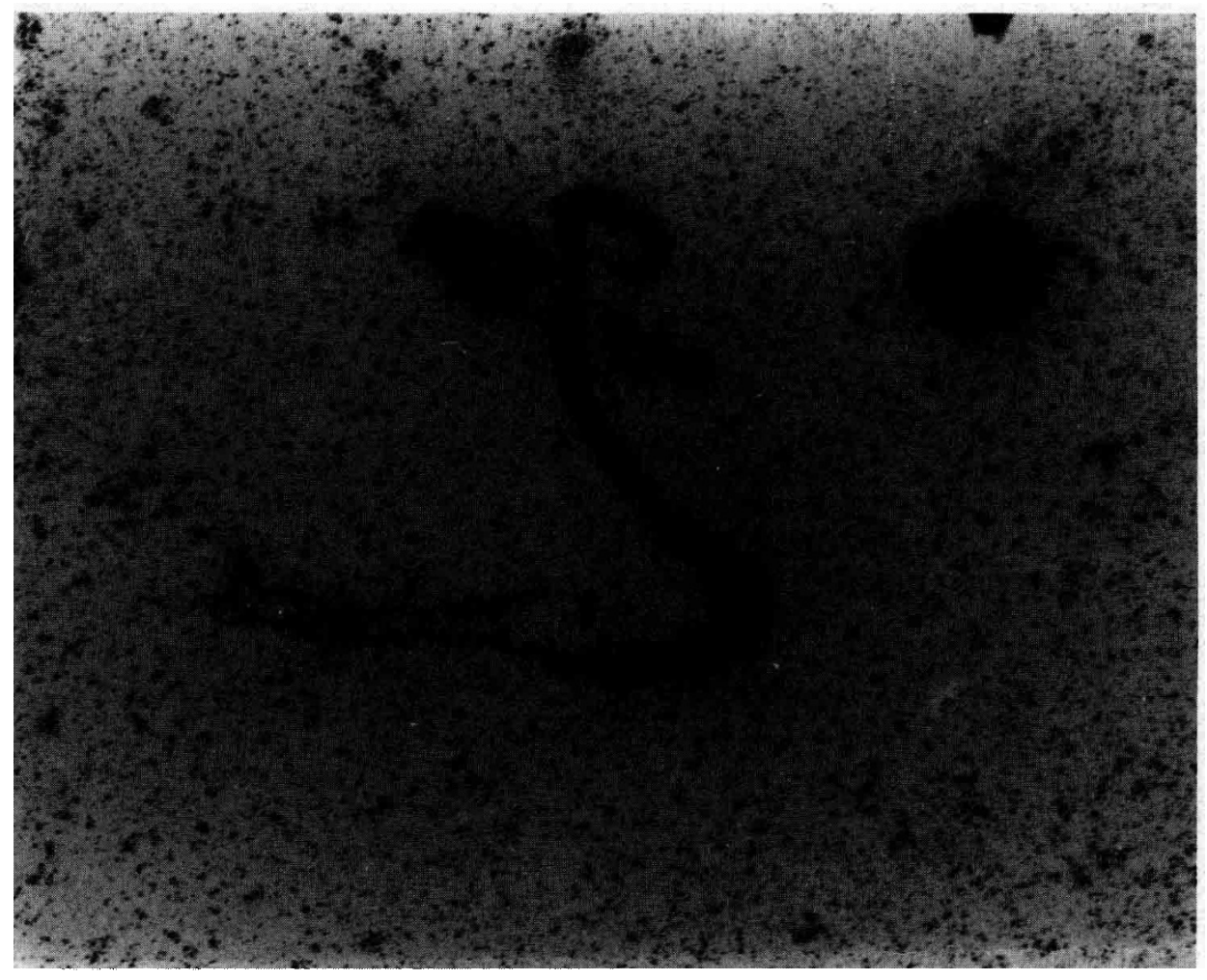

Fig 3. Early pachytene stage. Approximately $90 \%$ of the Y axis has synapsed with part of the $\mathrm{X}$ chromosome to form a synaptonemal complex. The differential region of the $\mathrm{X}$ retains an appearance similar to that in figure 2. Magnification: $21000 \times$.

substages (Solari, 1980; Greenbaum et al, 1986). According to these authors, the compaction and dilatation of the differential region characterize the early and midpachytene. We can observe this feature in figures 2,3 and 4 . The late pachytene is characterized by 'cracks' in the differential region (fig 4). In goats, at least 3 pachytene substages were identified, ie early, mid- and late pachytene, considering the changes in the $\mathrm{X}$ chromosome differential region, since the $\mathrm{Y}$ chromosome is fully paired with the $\mathrm{X}$. The full pairing of the $\mathrm{Y}$ axis with the $\mathrm{X}$ has already been observed in other mammalian species, such as rats (Joseph and Chandley, 1984) and cats (Gillies and Cowan, 1985). According to Solari (personal communication), such a complete pairing occurs when chromosome $\mathrm{Y}$ is very small in comparison to the size of the $\mathrm{X}$ chromosome. 

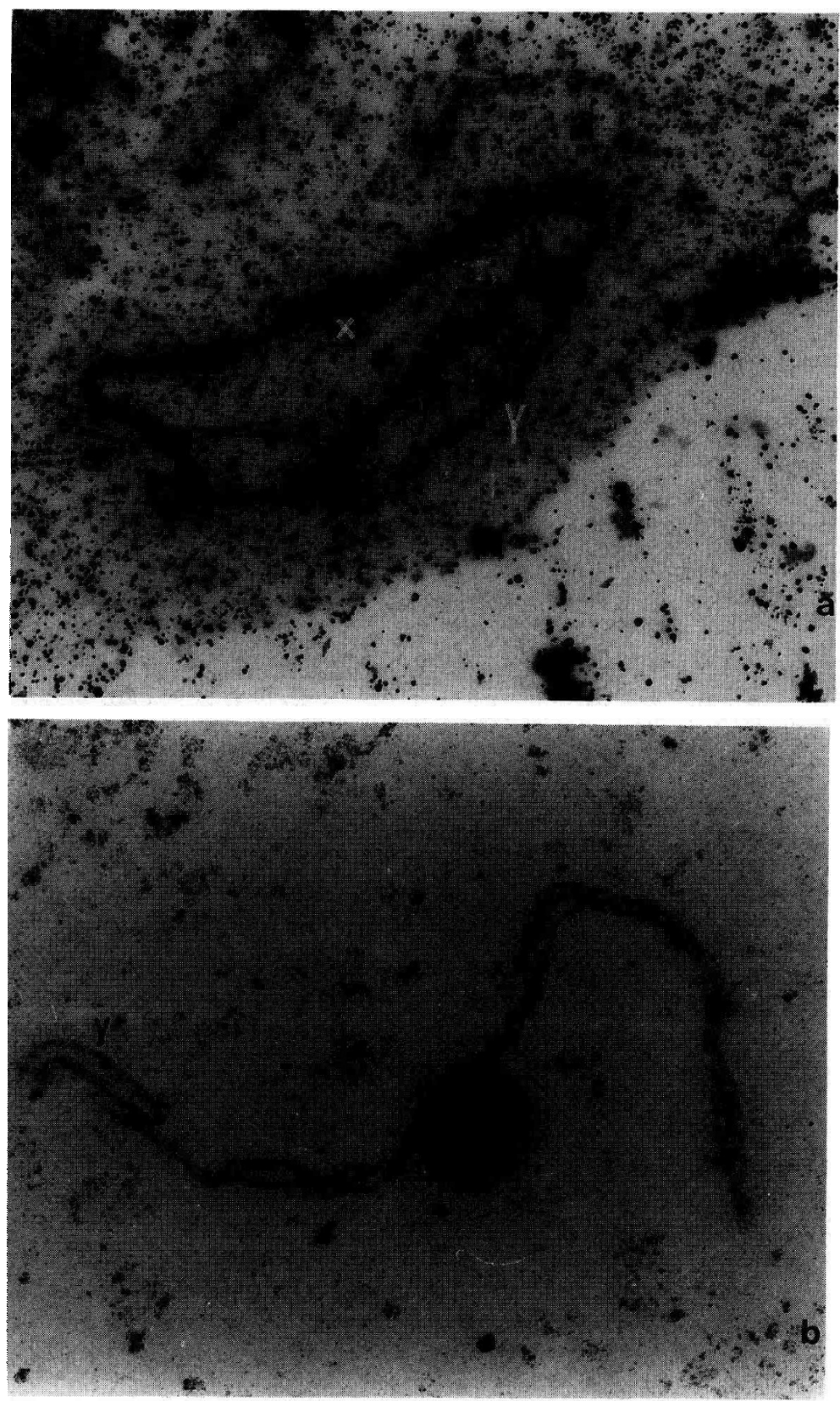

Fig 4. Sex bivalent at mid- and late pachytene (respectively), which show the full pairing of the $\mathrm{Y}$ axis with the $\mathrm{X}$. The late pachytene is characterized by 'cracks' in the differential region. Magnification: a. $16500 \times$, b. $21000 \times$. 


\section{ACKNOWLEDGMENTS}

We would like to thank A Solari, University of Buenos Aires, for helping in the technique adaptation, Y Yonenaga-Yassuda, Bioscience Institute, USP, São Paulo, for assistance in the analysis of results, E A Gregório and MH Moreno, Electron Microscopy Center, IB, NESP, Botucatu, for utilization of the electron microscope and CAPES for supporting the project.

\section{REFERENCES}

Gillies CB, Cowan SK (1985) The pachytene synaptonemal complex complement of the cat. Genetica $67,99-107$

Greenbaum IF, Hale DW, Fuxa KP (1986) The mechanism of autosomal synapsis and the substaging of zygonema and pachynema from deer mouse spermatocytes. Chromosoma 93, 203-212

Howell WM, Black DA (1980) Controlled silver staining of nucleolus organizer regions with a protective colloidal developper: a 1-step method. Experientia 36, 1014-1015

Joseph AM, Chandley AC (1984) The morphological sequence of XY pairing in the Norway rat Rattus norvegicus. Chromosoma 89, 381-386

Moses MJ (1977) Synaptonemal complex karyotyping in spermatocytes of Chinese hamster (Cricetulus griseus). II. Morphology of the XY pair in spread preparations. Chromosoma $60,127-137$

Solari AJ (1970) The spatial relationship of the X and Y chromosome during meiotic prophase in mouse spermatocytes. Chromosoma 29, 217-236

Solari AJ (1980) Synaptonemal complexes and associated structures in microspread human spermatocytes. Chromosoma $81,315-337$ 